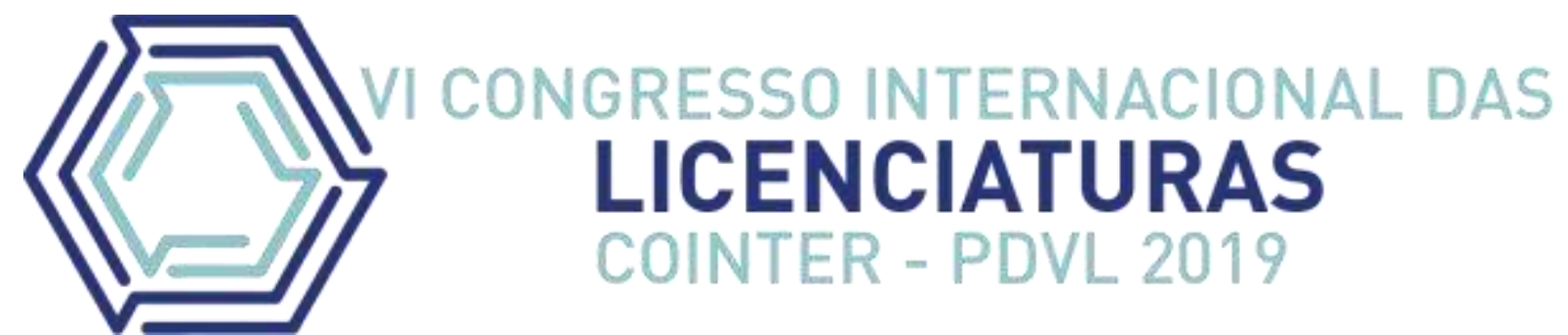

\title{
A INSERÇÃO DO ESPAÇO INTERNO E EXTERNO ESCOLAR INTERLIGANDO- SE AO FUNCIONAMENTO DIDÁTICO ATRAVES DE NOVAS METODOLOGIAS \\ DE ENSINO NA DISCIPLINA DE CIÊNCIAS DO FUNDAMENTAL I
}

\author{
LA INSERCIÓN DEL ESPACIO ESCOLAR INTERNO Y EXTERNO QUE SE \\ INTERLIGE A LA OPERACIÓN DIDÁCTICA A TRAVÉS DE NUEVAS \\ METODOLOGÍAS DE ENSEÑANZA EN LA DISCIPLINA DE LAS CIENCIAS \\ FUNDAMENTALES I
}

\section{THE INSERTION OF THE INTERNAL AND EXTERNAL SCHOOL SPACE INTERLIGING TO THE DIDACTIC OPERATION THROUGH NEW METHODOLOGIES OF TEACHING IN THE DISCIPLINE OF FUNDAMENTAL SCIENCES I}

\author{
Apresentação: Comunicação Oral
}

Maria Carliana do Nascimento Silva ${ }^{1}$; Márcia Queiroz de Lucena ${ }^{2}$; Dan Vítor Vieira Braga ${ }^{3}$

DOI: https://doi.org/10.31692/2358-9728.VICOINTERPDVL.2019.0005

\begin{abstract}
Resumo
\footnotetext{
1 Licenciatura em Ciências Biológicas, FACHUSC, Carliananascimento@outlook.com

${ }^{2}$ Graduada em Pedagogia, E.E.I.F.Francisco Alves Gondim,Marcialq74@gmail.com

3 Mestre em Gestão e Politicas Ambientais, FACHUSC,bragadvv@gmail.com
}

O ensino de Ciências é um espaço importante para o aprendizado da criança no ambiente escolar, e nos primeiros anos da Educação Básica. Este ensino deve contribuir para que os alunos sejam inseridos em uma nova cultura, a cultura científica. Objetivou-se com este estudo, observar e analisar as estruturas físicas e funcionais da escola sendo investigada a viabilidade de novos métodos de ensino através de ferramentas que proporcione novas metodologias de ensino-aprendizagem. O estudo foi desenvolvido em uma escola na cidade de Serrita-PE. Teve como base uma abordagem qualitativa sendo utilizados os métodos a seguir: observação, análise e aplicação com ênfase no ensino de Ciências. Constatou-se uma visão de inovar as práticas pedagógicas e inserir metodologias de ensino na disciplina de Ciências, sendo assim seguido aplicado a temática do PPP. Com potencial de exploração nas aulas e ferramentas disponíveis observou-se Auditório, Banheiros, Cantina e espaços internos e externos ao prédio escolar. Contudo alguns professores preferem usar o método mais tradicional através de cópias de resumo dos conteúdos, leitura e atividades. Percebeu-se um vasto leque de recursos de infraestruturas que podem ser utilizados no ensino de Ciências, porém as famílias possuem poder aquisitivo diferenciado. No entanto, o conteúdo foi realizado em sala no decorrer de quatro aulas onde os alunos participaram, com excursão fora do ambiente escolar percebeu-se muita empolgação na realização da atividade, com aproveitamento positivo nos alunos divido a mesclagem de ambientes distintos associando a 
conteúdo da realidade vivida pelos mesmos. Conclui-se que o sucesso de ensino e aprendizagem está em um conjunto de fatores e para que o Ensino de Ciências possa despertar a curiosidade do docente e no aluno em aprender e aplica-los.

Palavras-Chave: Ensino de Ciências, Ferramenta Didática, Ensino, Aprendizagem.

\title{
Resumen
}

La enseñanza de las ciencias es un espacio importante para el aprendizaje de los niños en el entorno escolar y en los primeros años de la educación básica. Esta enseñanza debería contribuir a que los estudiantes se inserten en una nueva cultura, la cultura científica. El objetivo de este estudio fue observar y analizar las estructuras físicas y funcionales de la escuela e investigar la viabilidad de los nuevos métodos de enseñanza a través de herramientas que proporcionan nuevas metodologías de enseñanza-aprendizaje. El estudio fue desarrollado en una escuela en la ciudad de Serrita-PE. Se basó en un enfoque cualitativo utilizando los siguientes métodos: observación, análisis y aplicación con énfasis en la enseñanza de las ciencias. Se verificó una visión de innovar las prácticas pedagógicas e insertar metodologías de enseñanza en la disciplina de Ciencias, siguiendo así el tema PPP. Con potencial para la exploración en las clases y herramientas disponibles, observamos el auditorio, los baños, la cantina y los espacios internos y externos al edificio de la escuela. Sin embargo, algunos maestros prefieren usar el método más tradicional a través de copias resumidas de contenido, lectura y actividades. Notamos una amplia gama de recursos de infraestructura que se pueden utilizar en la educación científica, pero las familias tienen un poder adquisitivo diferente. Sin embargo, el contenido se llevó a cabo en el aula durante cuatro clases en las que los estudiantes participaron, con excursiones fuera del entorno escolar, se realizó mucha emoción en la actividad, con un uso positivo en los estudiantes dividiendo la fusión de diferentes entornos que asocian el contenido del aula. realidad vivida por ellos. Se concluye que el éxito de la enseñanza y el aprendizaje radica en un conjunto de factores y que la Enseñanza de las Ciencias puede despertar la curiosidad del maestro y del alumno por aprenderlos y aplicarlos.

Palabras Clave: Enseñanza de las ciencias, herramienta didáctica, enseñanza, aprendizaje.

\begin{abstract}
Science teaching is an important space for children's learning in the school environment, and in the early years of basic education. This teaching should contribute for students to be inserted in a new culture, the scientific culture. The objective of this study was to observe and analyze the physical and functional structures of the school and to investigate the viability of new teaching methods through tools that provide new teaching-learning methodologies. The study was developed in a school in the city of Serrita-PE. It was based on a qualitative approach using the following methods: observation, analysis and application with emphasis on science teaching. It was verified a vision of innovating the pedagogical practices and inserting teaching methodologies in the Science discipline, being thus followed the PPP theme. With potential for exploration in the available classes and tools, we observed Auditorium, Bathrooms, Canteen and internal and external spaces to the school building. However some teachers prefer to use the more traditional method through summary copies of content, reading and activities. We noticed a wide range of infrastructure resources that can be used in science education, but families have different purchasing power. However, the content was held in the classroom during four classes in which students participated, with excursions
\end{abstract}


outside the school environment a lot of excitement in the activity was realized, with positive use in the students divide the merge of different environments associating the content of the classroom. reality lived by them. It is concluded that the success of teaching and learning lies in a set of factors and so that Science Teaching can arouse the curiosity of the teacher and the student to learn and apply them.

Keywords: Teaching Science, Didactics Tools, Teaching Learning.

\section{Introdução}

A educação, dever da família e do Estado, inspirada nos princípios de liberdade e nos ideais de solidariedade humana, tem por finalidade o pleno desenvolvimento do educando, seu preparo para o exercício da cidadania e sua qualificação para o trabalho (LDB, Art.2 ${ }^{\circ}$, 2017).

Segundo Cardoso (2013), o papel da escola constitui-se em preparar o aluno para as diversas situações da vida, porém atualmente a educação está sendo muito comentada, pois há anos, e cada vez mais, vem se buscando alternativas de tornar os métodos de aprendizagem mais significativos, que promovam a autonomia das pessoas e, principalmente, desperte o interesse dos estudantes em aprender.

O ensino de Ciências é um espaço importante para o aprendizado da criança no ambiente escolar, e nos primeiros anos da Educação Básica, poder conhecer e compreender os fenômenos naturais despertando seu interesse e a sua curiosidade para o mundo (SPERANDIO et al, 2017). Porém o método é a ferramenta que irá fazer grande diferença no processo ensino-aprendizagem, o que torna de suma importância à exploração de todas as fontes metodológicas possíveis no cotidiano curricular (RODRIGUES; BRAGA, 2017).

No entanto, para se alcançar uma educação de qualidade torna-se necessário que a escola disponha de uma boa estrutura, podendo assim favorecer o processo de ensinoaprendizagem, como também dispor de professores qualificados que estejam dispostos a inovar suas metodologias de ensino podendo interligar os conteúdos abordados com as vivências do cotidiano dos alunos. Pereira e Souza (2004) ressaltam ainda que os conteúdos devem ser tratados de forma globalizada valorizando as experiências do cotidiano dos alunos, permitindo as relações entre teoria e prática, dando significado ás aprendizagens realizadas na escola, possibilitando que estas sejam uteis na vida, no trabalho e no exercício da cidadania.

Como afirma Lima e Vasconcellos (2006) à temática sobre meio ambiente é constantemente abordada em jornais, revistas, televisão e internet, o que aguça a curiosidade dos alunos do Ensino Fundamental. Portanto, objetivou-se com este estudo observar e analisar 
as estruturas físicas e funcionais da escola sendo observada a viabilidade de novos métodos de ensino através de ferramentas que proporcionem novas metodologias de ensino-aprendizagem para Ciências Naturais.

\section{Fundamentação Teórica}

O ensino de ciências deve contribuir para que os alunos sejam inseridos em uma nova cultura, a cultura científica, a qual lhes possibilitará ver e compreender o mundo com um pensamento crítico e conhecimentos para discernir, julgar e fazer escolhas conscientes em seu cotidiano, com vistas a uma melhor qualidade de vida (VIECHENESKI; CARLETTO, 2012).

De acordo com Viecheneski, Lorenzetti e Carletto (2012), a importância de ensinar Ciências é reconhecida por pesquisadores da área, havendo uma convergência de opiniões quanto aos seus objetivos, tendo em vista as inúmeras inter-relações que o ser humano com o ambiente e vice-versa e as demandas que isso gera para a formação dos sujeitos, haja vista ele é parte do meio. Os de ciências naturais do Ensino Fundamental devem ser abordados por meio de temas sociocientíficos, só assim será capaz de superar a visão fragmentada que tem marcado esse ensino proporcionando mais impacto positivo no cidadão (MUNDIM; SANTOS, 2012).

Lima e Vasconcellos (2006) afirmam que os alunos do ensino fundamental da rede pública na maioria das vezes deparam-se com metodologias que nem sempre promovem a construção de seu conhecimento e cabe apenas ao professor tentar inovar seus métodos de ensino para que estes sejam capazes de estimular aos alunos na busca pela compreensão e construção de seu próprio conhecimento. Ao professor, incumbe as funções de articular conhecimentos facilitando o entendimento com as propostas pedagógicas da instituição escolar, mas é papel do mesmo buscar articulações entre o que propõe e realiza em sala de aula com aspectos da comunidade que frequenta aquela escola propiciando maior envolvimento (SASSERON; DUSCHL, 2016).

Para Oliveira e Gastal (2009), o processo de ensino-aprendizagem pode ter sua eficácia melhorada quando o conhecimento trabalhado se torna mais facilmente assimilável pelo aluno e essa assimilação acontece, em maior ou menor grau, de acordo com os métodos e técnicas empregados. Embora o livro didático seja importante dentro do contexto educacional, ele sozinho não obtém êxito nas tarefas de alfabetização e letramento científico e tecnológico necessário para que os alunos desenvolvam habilidades e competências, torna-se necessário o 
professor em sua prática pedagógica utilizar outros recursos pedagógicos para potencializar o processo de formação desses cidadãos (AMARAL; XAVIER; MARCIEL, 2009).

Segundo Nicola e Paniz (2009), as aulas práticas, quando bem elaboradas, atuam com contraponto das aulas teóricas e aceleram o processo de aquisição dos novos conhecimentos e a realização de experimentos facilita a fixação do conteúdo, complementando a teoria e para que sejam realizadas essas atividades não é necessário um excelente laboratório com os melhores materiais, sendo possível também realizar experiências práticas dentro da sala de aula ou fora da mesma sendo importante deixar que o aluno manipule os materiais, produza algo ou mesmo observe por si próprio um fenômeno, uma experiência etc.

De acordo com Bevilacqua e Silva (2007), as atividades experimentais são ferramentas preciosas para o ensino de ciências e é fundamental que o aprendiz perceba os fenômenos científicos no seu cotidiano e que o "fazer ciência" possa fazer parte do seu pensamento.

Segundo Viecheneski e Carletto (2012), o ensino de ciências nos anos iniciais pode auxiliar na construção de valores e habilidades que possibilitarão aos alunos continuarem aprendendo, pois as atitudes e valores se constroem desde cedo e quando a escola proporciona momentos para debates, questionamentos, reflexões, exposição e confronto de ideias, abre a oportunidade de ensinar valores essenciais ao exercício da cidadania, como respeito pelas diferentes ideias, tolerância, cooperação, respeito à diversidade, as regras combinadas em grupo, capacidade de se comunicar, de ouvir e esperar sua vez para se expressar, responsabilidade, senso crítico e inclusão social.

A investigação escolar é uma atividade multifacetária que envolve observações, perguntas, examinar livros e outras fontes de informação para ver o que se conhece a respeito, planejar pesquisas, rever o que se sabia em função de nova evidência experimental, assim tendo um maior arcabouço didático surgindo ferramentas para compilar, analisar e interpretar dados, propor respostas, explicações e predições e comunicar os resultados (FUMAM, 2009).

Segundo Viveiro e Diniz (2009), os problemas financeiros que impossibilitam o custeio do transporte para excursões e aulas distantes a escola podem ser contornados com a realização de atividades próximas ao ambiente escolar. Basta ter um olhar atento para que inúmeras possibilidades surjam ali, bem perto ao campo de ensino sendo viável para escola, alunos e professor.

\section{Metodologia}


O estudo foi desenvolvido em uma escola na cidade de Serrita-PE(Figura 1). O município está localizado na microrregião de Salgueiro, na mesorregião do sertão central, a sua população e de aproximadamente 18.331hab.com uma área de $1.538 .437 \mathrm{~km}^{2}$, com distância de $535 \mathrm{~km}$ da sede do município a capital do estado (IBGE, 2016). A área abordada para obtenção de dados foi a escola Municipal Menino Jesus, que tem funcionamento em dois turnos (manhã e tarde), com a modalidade de ensino fundamental I.

Figura 1 - A. Visão geral do município no estado de Pernambuco; B. Escola Municipal Menino Jesus. Fonte: Própria
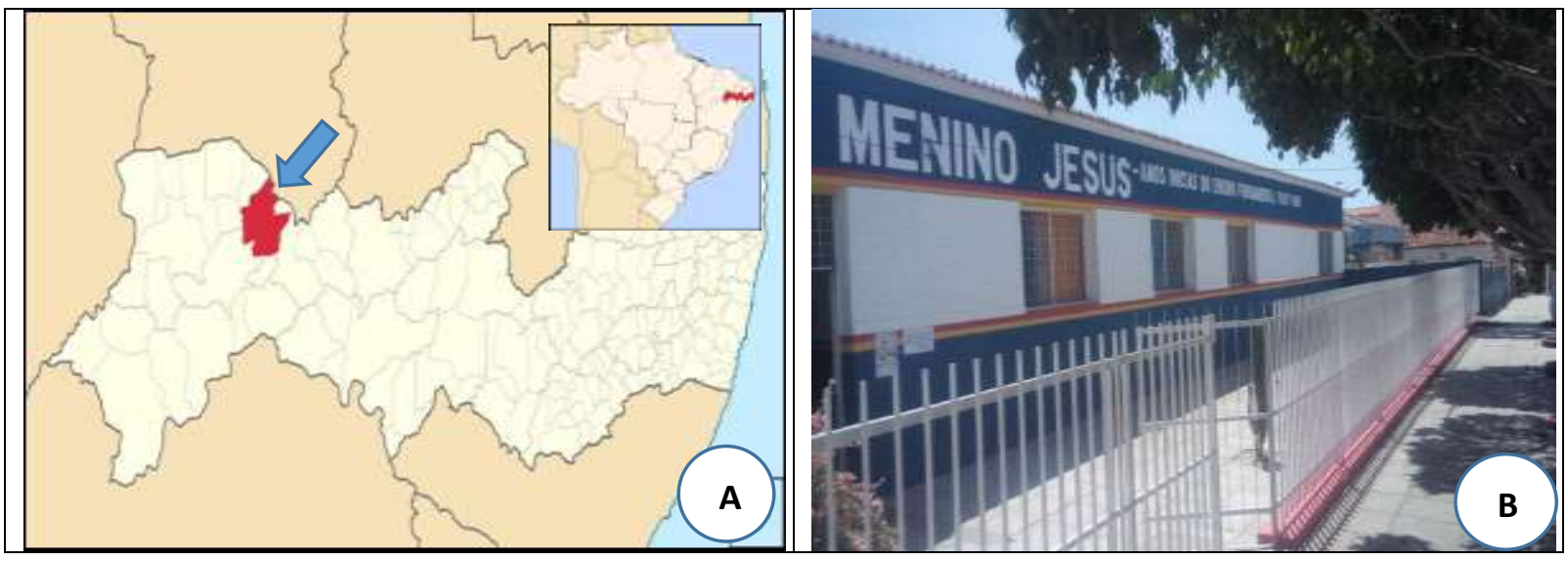

O presente trabalho baseou-se em uma abordagem qualitativa. Deu-se em um período de 11 meses (Agosto de 2018 a junho de 2019), para obtenção dos dados foram utilizados os métodos a seguir: observação, análise e aplicação com ênfase no ensino de Ciências. Esta pesquisa contou com o fomento do governo federal, através do Programa Residência Pedagógica - CAPES/MEC.

Analisou-se o Projeto Político Pedagógico (PPP), sendo verificada a implementação do mesmo na escola e aplicação no funcionamento didático do que está proposto no PPP.

Observaram-se as estruturas físicas internas e externas da escola associando-o ao funcionamento pedagógico e avaliando quais locais poderiam ser utilizados para aplicar o ensino de Ciências, fazendo novas inserções metodológicas podendo interligar o contexto das famílias ao processo de ensino-aprendizagem.

Para teste da aplicabilidade do método proposto para inovação no ensino de ciências na escola campo, foi aplicada uma ferramenta didática a qual dividiu-se em etapas:1. Na sala, foi feita explanação do conteúdo. 2. Após isso, foi realizada uma listagem dos os materiais a serem utilizados na aula de campo (água, luvas, colher ou pá, sacos plásticos, funis, algodão, copos de plástico transparentes, cronômetro). 3. Foi utilizado o ambiente externo à escola 
através de aula de campo para coleta, análise e identificação do material coletado sendo realizado experimento.

\section{Resultados e Discussão}

\section{Projeto Político Pedagógico da Escola Campo}

Constatou-se que a escola visa o bom desenvolvimento da educação, estando disposta a formar cidadãos com conhecimentos e atitudes, éticos, críticos, solidários e atuantes na sociedade. Assim, tomado em sentido amplo, tornando um meio pelo qual crianças, jovens e adultos são expostos a um conhecimento elaborado e fundado em fatos e teorias do cotidiano, proporcionando o desafio de ensinar e aprender (VIEIRA, 2010).

Observou-se que a escola deve contar com a participação de toda a comunidade para que juntos possam traçar metas para atender as necessidades que venham surgir no cotidiano escolar dos alunos, visando inovar as práticas pedagógicas e inserir metodologias de ensino na disciplina de Ciências, sendo assim seguido aplicado a temática do PPP. Haja vista que o Parâmetro Curricular Nacional (PCN, 1998), tem como objetivo Ciências Naturais no Ensino Fundamental é instigar para que o aluno desenvolva competências que lhe permitam compreender o mundo e atuar como indivíduo e ser sociável.

Ambiente Interno à Escola Campo

A escola conta com algumas estruturas físicas: 01 sala de direção; 01 Sala de Secretaria; 01 Sala de Coordenação e Professores; 12 salas de aulas.

No entanto, o colégio possui um total de 22 professores os quais atendem a um total de 610 alunos, sendo que alguns destes alunos possuem necessidades especiais. Estes ainda possuem realidades de vida diferentes, pois alguns são da zona urbana e outros da zona rural, no entanto segundo Moreno (2016) a escola é um espaço de múltiplos saberes que acomoda e acolhe a diversidade, respeita o direito de todos e está comprometida em oferecer um ensino de qualidade.

A respeito do campo com potencial de exploração nas aulas de Ciências observou-se Auditório, Banheiros Cantina e espaços abertos internos que circundam o prédio escolar. Assegurando a colocação feita pelo (SESC), Departamento Nacional (2015), ao citar que é possível acessar as informações sobre o mundo, fazer as articulações e organizações necessárias, para perceber e conceber o contexto global ampliando-se o conceito de ciência interpretando os fatos humanos nas dimensões éticas e estéticas.

Figura 2 - Aspecto geral dos departamentos presentes no meio interno da escola campo de estudo. A. 
Auditório; B. Cozinha; C. Meio entre muro de acesso e escola.

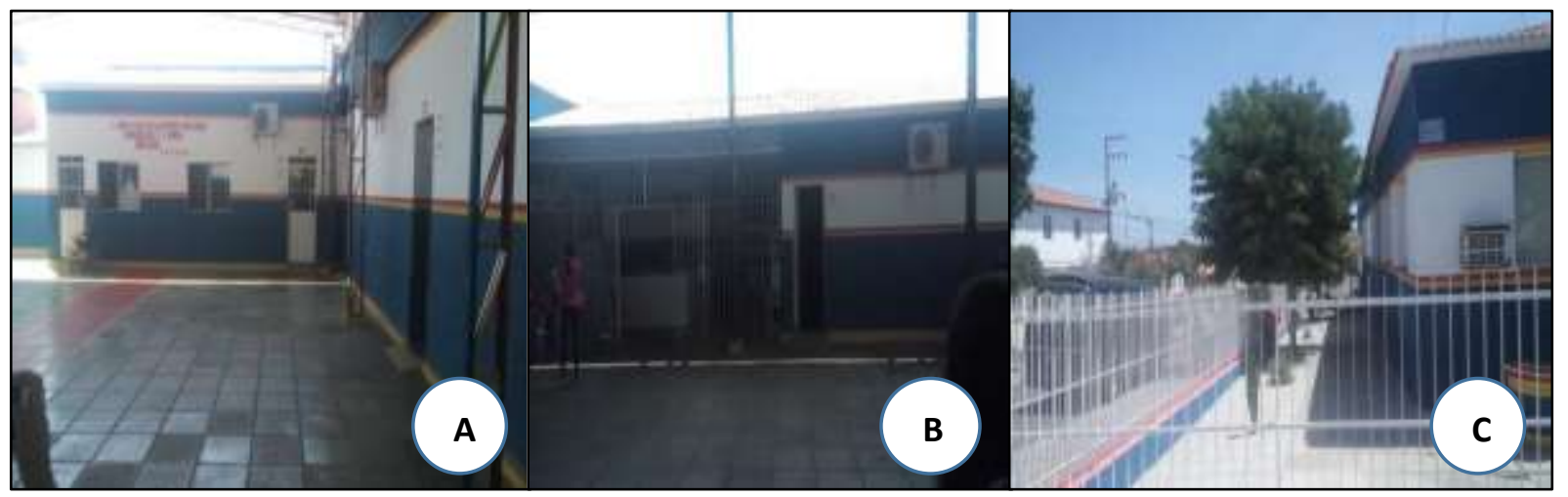

Fonte: Própria, (2019).

$\underline{\text { A aula de Ciências }}$

Constatou-se um funcionamento em dois turnos, manhã e tarde, as aulas com inicio ás $07 \mathrm{~h} 30 \mathrm{~min}$ e terminam às $11 \mathrm{~h} 30 \mathrm{~min}$, configura-se primeiro turno sendo das $13 \mathrm{~h} 00 \mathrm{~min}$ as 17h00min o segundo turno. Como forma de despertar o interesse dos alunos alguns professores explicam suas aulas através de slides, músicas e vídeos. No entanto, o professor deve, em primeiro lugar, sentir-se desconfortável com o sistema metodológico de ensino, segundo ter tempo e vontade para elabora um planejamento diferente que envolva os alunos e possa fornecer a construção de conhecimento (WEBER, 2007).

Vale ressaltar, que alguns preferem usar o método mais tradicional através de copias de resumo dos conteúdos, leitura e atividades, porém estes professores poderiam tornar suas aulas mais interessantes despertando a curiosidade dos alunos e estimula-los a resolver pequenos problemas que possam surgir em seu cotidiano. Corroborando com Cardoso (2013) ao afirma que as aulas práticas proporcionam momentos de interação entre professor e alunos, em que o último, não é somente o receptor do conhecimento tomando outro foco, não somente o de transmitir informações.

Com relação à ferramenta viável, percebeu-se que seria aulas de campo e experimentos que não requerem grandes custos entre vários outros métodos de ensino que poderiam ser utilizados para despertar interesse das crianças. Vale salientar o método por investigação uma vez que o mesmo é capaz de abarcar um arcabouço de possibilidade de aprendizagem de forma que o estudante tenha oportunidades de interagir com o objeto de estudo e com seus pares para organizar o pensamento e elaborar explicações sobre o mundo utilizando-se de conceitos científicos (URSI; SCARPA, 2016).

Ambiente Externo à Escola Campo 
O entorno da escola percebeu-se um vasto leque de recursos de infraestruturas que podem ser utilizados no ensino de Ciências, estes que são Praça com arborização, Fórum jurídico, Hospital, Feira livre e Mercado Público (figura 3). O que possibilita o ensino por investigação, corroborando com Ursi e Scarpa (2016), ao afirmar que a coleta de dados e informações se realizada por meio de diferentes estratégias didáticas: observações, comparações entre fenômenos, livros, internet, filmes, jogos, simulações, etc. Tendo uma contextualização a situação de pesquisa podendo ser efetivamente respondidas por meio da construção conjunta de explicações sustentadas em evidências coletadas de diversas fontes.

Figura 3 - Aspecto geral dos departamentos presentes no meio externo da escola campo do estudo. A. Praça; B. Fórum; C. Hospital; D. Mercado. Publico; E. Feira. Livre.

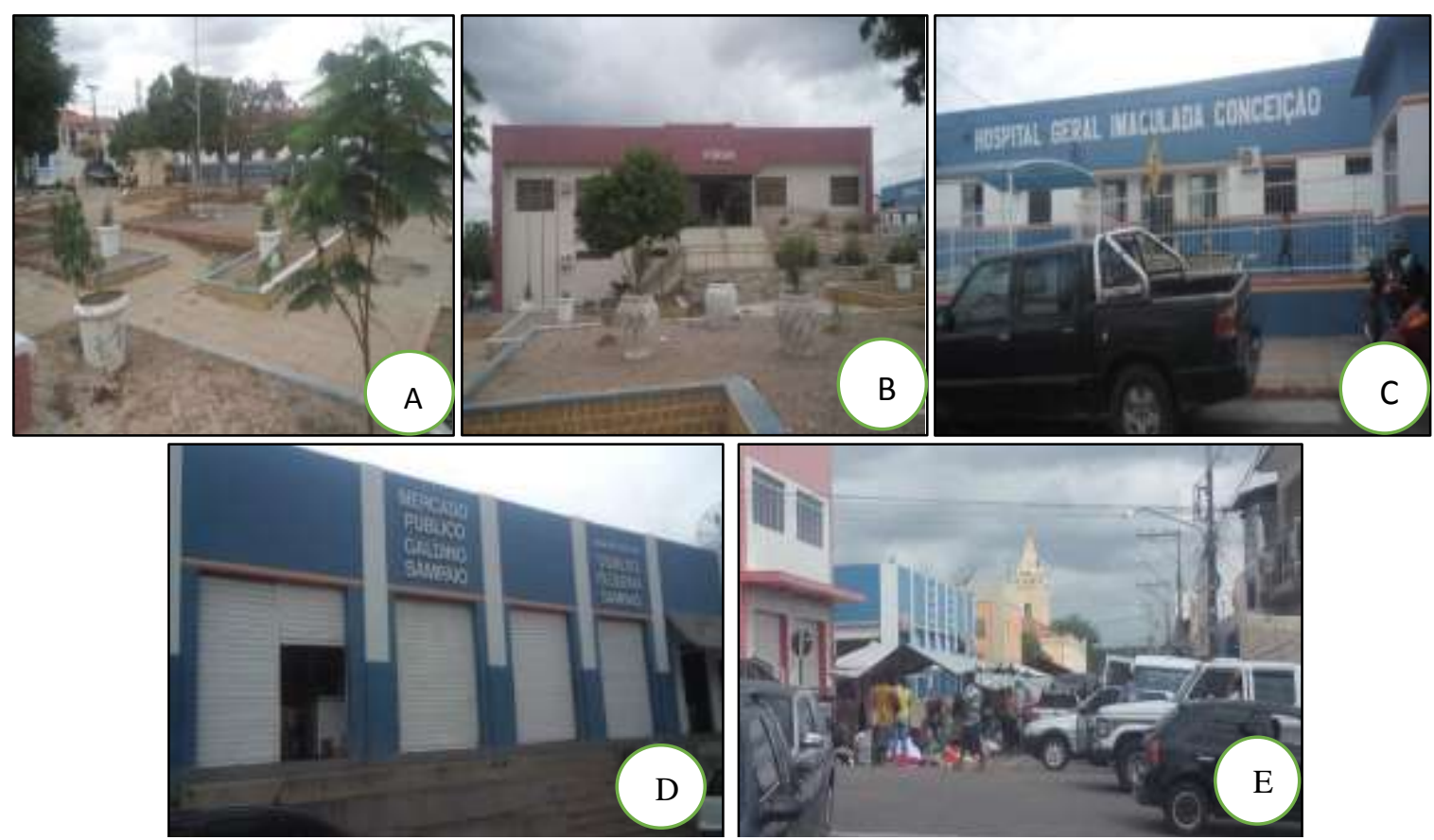

Fonte: Própria, (2019).

Vale enfatizar que estes espaços são essenciais para que os professores possam aplicar novas metodologias de ensino e algumas delas seriam aulas de campo, pesquisas, aulas experimentais dentro ou fora da sala de aula. Como enfatiza Basílio (2016), podemos na proposta privilegiar a aprendizagem que hora privilegie a aprendizagem individual, ora ela se realize coletivamente, mas que tenha como desafio comtemplar a produção final e individual. Ambiente Familiar

Com relação às residências das famílias, estas são diversificados, porém os mesmos possuem poder aquisitivo diferenciado, o que não isenta a obrigatoriedade da família estar preocupada com e educação e desenvolvimento escolar do seu filho, portanto procurar está 
presente podendo auxilia-lo neste processo de ensino e aprendizagem. Uma vez que o Parâmetro Curricular Nacional (1997), enfatiza que a aprendizagem provém do envolvimento ativo do aluno com a construção do conhecimento e as ideias prévias, possuindo papel fundamental na aprendizagem, que só é possível embasada naquilo que ele já sabe.

Quando os pais acompanham o desenvolvimento escolar dos seus filhos auxiliam nas atividades que são passadas em sala, estes possuem capacidade de ajudar aos alunos associarem os conteúdos vistos e relaciona-los com tudo aquilo que está presente no seu diaa-dia. Segundo Casarin e Ramos (2007) Acredita-se que a família e a instituição escolar compartilham a mesma função educacional, embora uma não possa fazer o papel da outra.

Aplicação de Método e Ferramenta de Inovação

Com relação à explanação do Conteúdo foi realizada em sala no decorrer de quatro aulas onde os alunos participaram, ao serem questionados sobre o assunto comparando com as vivencias do seu cotidiano, mostrando como ocorre o processo de formação dos solos, importância e quais atividades podem prejudicar o solo. Isto atesta a afirmativa feita por Fabri e Silveira (2013), ao citar que esses cidadãos poderão atuar e intervir na realidade o qual estão inseridos, mas para que essa intervenção aconteça é necessário que a escola, possa modificar o modo de ensinar, levando em consideração a realidade vivenciada pelos alunos.

Como seguimento da temática proposta foi utilizado os materiais acima citado para a aula de campo (água, luvas, colher ou pá, sacos plásticos, funis, algodão, copos de plástico transparentes, cronômetro). Os alunos realizaram a coleta de alguns tipos de solo fora do ambiente escolar, sendo que cada aluno ficaria responsável pela sua coleta (figura 4).

Figura 4. Aplicação e desenvolvimento da ferramenta didática com alunos, A. coleta em Praça B coleta ambiente próximo a escola, $\mathrm{C}$ demonstração de experimento.
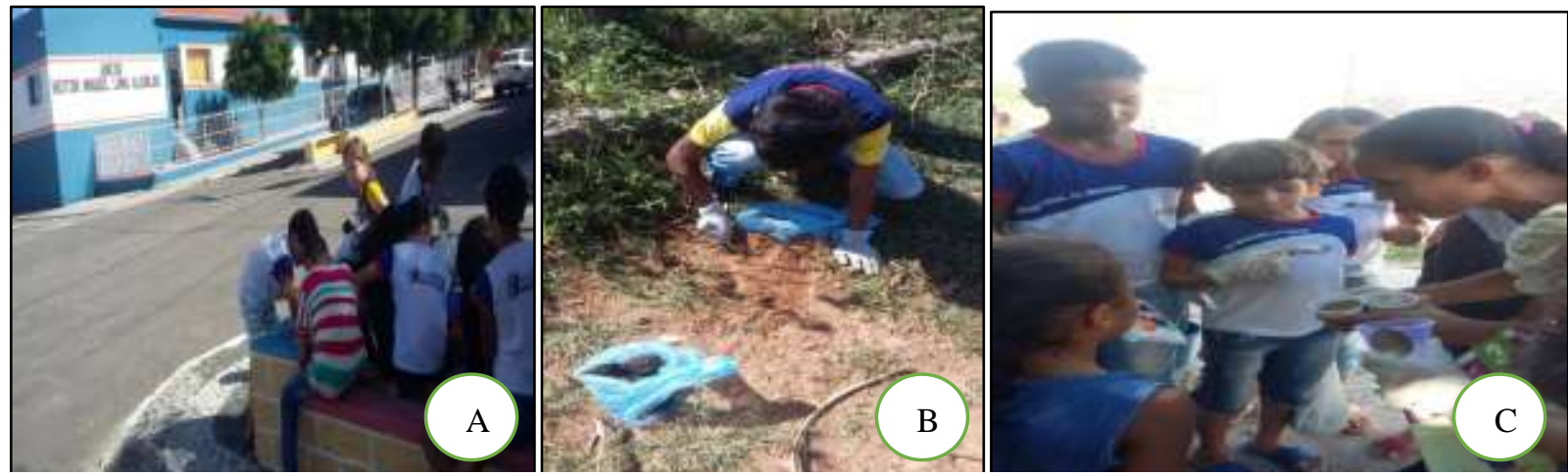

Fonte própria, (2019).

Com relação ao desenvolvimento, haja vista os mesmo não tinham hábito de aulas no meio externo, para análise do experimento no ambiente interno de escola, porem fora da sala 
de aula comprovando que é possível utilizar vários ambientes para fins de aprendizagem. $\mathrm{O}$ que é de suma importância para mudar a rotina afirmada por Seniciato e Cavassan, (2004), o ensino pautado somente nas ideias, no abstrato e, sobretudo, na fragmentação do conhecimento tem contribuído para um desinteresse, indiferença e um desprezo em relação ao conhecimento e busca por algo novo.

Constatou-se um desenvolvimento e aproveitamento positivo nos alunos divido a mesclagem de ambientes distintos associando a conteúdo da realidade vivida pelos mesmos, assim sendo possível comparar realidade e ficção. A satisfação sentido pelos alunos no decorrer da aula de campo também tornou agradável o processo de aprendizagem, o que relaciona isto é o conforto de aprender apontado pelos alunos sendo decorrente de uma satisfação pessoal pela conquista de um novo saber, o que pode ser tema para novas pesquisas (SENICIATO E CAVASSAN, 2004).

\section{Conclusões}

Para que o Ensino de Ciências possa despertar no aluno a curiosidade em aprender, se faz necessário busquem aplicar novas metodologias de ensino contextualizado, capazes de transformar os alunos em cidadãos críticos e atuantes na sociedade. Porém, para que isso seja realizado é necessário que as famílias estejam preocupadas com a educação de seus filhos, buscando estar sempre presente na Escola e incentivar seus filhos para que possam desenvolver suas habilidades dentro e fora do ambiente escolar e, assim, conseguir enfrentar as novas situações que surgiram no seu dia-a-dia. Desta forma, constatou-se que o sucesso de ensino e aprendizagem está alicerçado em quatro pilares: Plano Político Pedagógico; Estrutura física/funcional da escola; Engajamento e inovação docente; Envolvimento familiar no contesto escolar, podendo assim proporcionar a finalidade do ensino proposto pelo Plano Politico Pedagógico que visa um desenvolvimento sócio/intelectual dos alunos como cidadão pensando e transformadores.

\section{Referências}

AMARAL, C. L. C; XAVIER, E. da. S; MACIEL, M. de. L. Abordagem das relações ciência/tecnologia/sociedade nos conteúdos de funções orgânicas em livros didáticos de química do ensino médio. Investigações em Ensino de Ciências - v14, n1, pp. 101-114, 2009. 
BASILIO, J. C. Os desafios da escola pública paranaense na perspectiva do professor pde Produções Didático-Pedagógicas. Versão online, ISBN978-85-8015-094-0, Cadernos PDE, v. II.

BRASIL. Parâmetros curriculares nacionais: ciências naturais / Secretaria de Educação Fundamental. - Brasília : MEC/SEF, 1997.

BEVILACQUA, G. D, SILVA, R. C. O ensino de Ciências NA $\mathbf{5}^{\mathrm{a}}$ série através de experimentação. Ciências \& Cognição 2007; vol. 10: 84-92. ISSN 1806-5821.

CARDOSO, F. de. S. O uso de atividades práticas no ensino de ciências: na buscar de melhores resultados no processo de ensino aprendizagem. centro Universitário Univates, Curso de graduação em licenciatura de Ciências Biológicas, Lajeado, dezembro de 2013.

CASARIM, N. E. F; RAMOS, M. B. J. Relato de experiência. Família e Aprendizagem Escolar. Rev. Psicopedagogia 2007; 24 (74): 182-201.

FABRI, F; SILVEIRA,R. M. C. F. O ensino de ciências nos anos iniciais do ensino fundamental sob a ótica cts: Uma proposta de trabalho diante dos artefatos tecnológicos que norteiam o cotidiano dos alunos. Investigações em Ensino de Ciências - V18(1), pp. 77-105, 2013

FUMAM, M. O ensino de ciências no ensino fundamental: colocando as pedras fundacionais do pensamento científico. São Paulo Sangari 2009.

IBGE. IBGEcidadesibge.gov.br. Atualizado em 2016,Disponível em http://ibge.gov.br2BMX.

LDB: Lei de Diretrizes e Bases da Educação Nacional- Brasilia: Senado Federal, Coordenação de Edições Técnicas,2017.

LIMA, K. E. C; VASCONCELLOS, S. D. Análise de metodologia de ensino de ciências nas escolas da rede municipal de recife. Ensaio: val. pol. públ. Educ. Rio de Janeiro, v.14, n.52, p.397-412, jul, set. 2006.

MUNDIM, J. V; SANTOS, W. L. P. dos. ensino de ciências no ensino fundamental por meio de temas sociocientíficos: análise de uma prática pedagógica com vista à superação do ensino disciplinar. Ciência \& Educação (Bauru), vol. 18, núm. 4, 2012, pp. 787-802 Universidade Estadual Paulista Júlio de Mesquita Filho São Paulo, Brasil.

NICOLA, J. A; PANIZ, C. M. A importância da utilização de diferentes recursos didáticos no ensino de biologia. Infor, Inov. Form., Rev. NEaD-Unesp, São Paulo, v. 2, n. 1, p.355-381, 2016. ISSN 2525-3476.

OLIVEIRA, R. I. R. de.; GASTAL.M. L. de. A Educação formal fora da sala de aulaolhares sobre o ensino de ciências utilizando espaços não-formais. VIIEnpec: Encontro Nacional de Pesquisa em Educação em Ciências,Florianópolis,8 de Novembro de 2009.p.611.ISSN 2176-6940. 
PARÂMETRO CURRICULAR NACIONAL: Algumas Dificuldades e Solução no Ensino e Aprendizagem de Ciências Naturais. Secretaria de Educação Fundamental - Brasília: MEC/SEF. 1998.

PEREIRA, L. C; SOUZA, N. A. Concepção e prática de avaliação: um confronto no ensino médio. Estudos em Avaliação Educacional: revista da fundação Carlos Chagas, São Paulo,n.29.2004.

RODRIGUES, F. W. A; BRAGA, D. V. V. O Ensino de Ciências Naturais na Educação Básica: Interligado os Métodos Indutivo e Cognitivo. Anais... IV Congresso Internacional das Licenciatura COINTER - PDVL 2017.

SASSERON, L. H; DUSCHL, R. A. ensino de ciências e as práticas epistêmicas: o papel do professor e o engajamento dos estudantes. Ienci. Investigação em ensino de Ciências V21(2) - Ago. 2016 pp. $52-67$.

SENICIATO, T; CAVASSAN, O. aulas de campo em ambientes naturais e aprendizagem em ciências - um estudo com alunos do ensino fundamental. Ciência \& Educação, v. 10, n. 1, p. 133-147, 2004.

SESC. DEPARTAMENTO NACIONAL. Proposta pedagógica [do] ensino fundamental; anos iniciais / Sesc, Departamento Nacional. -- Rio de Janeiro: Sesc, Departamento Nacional, 2015. 274 p.; $21 \mathrm{~cm}$.

SPERANDIO, M. R. da. C; ROSSIERI, R. A; ROCHA, Z. de. F. D. C; GOYA. A. O ensino de ciências por investigação no processo de alfabetização e letramento de alunos dos anos iniciais do ensino fundamental. UTFPR-Universidade Tecnológica Federal do ParanáLondrina. Experiências em Ensino de Ciências V.12,No.4 2017.

URSI, S; SCARPA, D. L. Ensino de Ciências por investigação: sequencia didática "Mata Atlântica - Restinga" / organizadoras Suzana Ursi; Daniela Lopes Scarpa. -- São Paulo: Instituto de Biociências, Universidade de São Paulo, 2016. 39 p.

VIEIRA, S. L. Estrutura e Funcionamento do Ensino Fundamental e Médio SECRETARIA DE EDUCAÇÃO A DISTÂNCIA(SEAD/UECE). Pouchin Ramos Gráfica \& Editora. 2010.

VIECHENESKI, J. P; CARLETTO, M. Por que e para quê ensinar ciências para crianças. III Simpósio Nacional de Ensino de Ciências e Tecnologia. Ponta Grossa - PR de 26 a 28 de Setembro 2012.

VIVEIRO, A. A; DINIZ, R. E. de, S. Atividades de campo no ensino das ciências e na educação ambiental: refletindo sobre as potencialidades desta estratégia na prática escolar. CIÊNCIAS EM TELA. Volume 2, Numero 1, 2009.

VIECHENESKI, J. P; LORENZETTI, L; CARLETTO, M. R. Desafios e práticas para o ensino de ciências e alfabetização científica nos anos iniciais do ensino fundamental. ATOS 
DE PESQUISA EM EDUCAÇÃO - PPGE/ME ISSN 1809-0354 v. 7, n. 3, p. 853-876, set./dez. 2012.

WEBER,S.S.F. Avaliação de Aprendizagem Escolar: Prática em novas perspectivas. Universidade Federal de Santa Maria (UFSM/RS). Santa Maria, Rs. Brasil 2007. 